\title{
Perforated jejunal diverticulum: a rare presentation of acute abdomen
}

\author{
Crystal Kavanagh, ${ }^{1}$ Christodoulos Kaoutzanis, ${ }^{1}$ Kristen Spoor, $^{1}$ Paul F Friedman ${ }^{2}$
}

${ }^{1}$ Department of Surgery, Saint Joseph Mercy Ann Arbor, Michigan, USA

${ }^{2}$ Department of Surgery, Saint Mary Mercy Livonia, Michigan, USA

\section{Correspondence to}

Dr Christodoulos Kaoutzanis, ckaoutzanis@gmail.com

Accepted 18 February 2014

\section{SUMMARY}

Jejunal diverticulosis is a rare entity with a reported clinical incidence of $0.5 \%$. However, symptoms relating to its presence are non-specific, which does not only delay diagnosis, but also increases the risk of serious complications approaching 15\%. We report a case of perforated jejunal diverticulum presented with a 6-month history of significant weight loss and acute abdominal pain. We discuss clinical presentation in both simple and complex cases, diagnostic pitfalls and management strategies.

\section{BACKGROUND}

Jejunal diverticulosis is a rare entity, with a reported clinical incidence of $0.5 \% .^{1}$ The nonspecific manner in which it typically presents however, with symptoms suggestive of malabsorption and chronic abdominal discomfort, can mask the true diagnosis. Alternative aetiologies, such as small bowel enteropathies, are usually considered. As such, the rate of serious complications necessitating operative intervention, namely bleeding and free perforation, can approach $15 \%$. $^{2}$

We present a rare cause of acute abdominal pain secondary to a perforated jejunal diverticulum. We also review the literature pertaining to imaging small bowel diverticula and options in their management.

\section{CASE PRESENTATION}

A 63-year-old man presented to the emergency department with a 2-day history of right lower quadrant pain, which remitted but later recurred with significant progression in intensity. He further endorsed a good appetite but a 6-month history of weight loss estimated at $16 \mathrm{~kg}$, which he attributed to stress. The patient had no significant medical history except for resolved Bell's palsy.

On physical examination our patient's vital signs were a temperature of $37.1^{\circ} \mathrm{C}$, heart rate $90 \mathrm{bpm}$, blood pressure $122 / 71 \mathrm{~mm} \mathrm{Hg}$, respiratory rate 16 and oxygen saturation $94 \%$ on room air. His abdominal examination was significant for mild distension and moderate right lower quadrant tenderness, without evidence of peritonitis. Laboratory investigations were significant for leucocytosis with a white cell count of $14400 / \mu \mathrm{L}$, hyperbilirubinaemia with a total bilirubin of 3.5 units $/ \mu \mathrm{L}$ and hypoalbuminaemia with an albumin of $2.1 \mathrm{~g} / \mathrm{dL}$. Urinalysis revealed urobilinuria.

Two-view abdominal X-ray revealed non-specific gaseous distension of the large and small bowel. Of note, a $10 \times 5$ centimeter radiopaque structure was visualised in the right lower quadrant. Subsequently, the patient underwent CT of the abdomen and pelvis (figure 1A,B) that revealed an area of apparent communication between rightsided loops of small bowel with visualised extraluminal gas. A calcific focus was also noted central to the involved segment.

On presumption of a small bowel perforation, the patient was taken to the operating room where he underwent exploratory laparotomy. A mass was noted in the right lower quadrant consisting of a perforated jejunal diverticulum with thickened adjacent mesentery and fibrinous debris. Several large diverticula were identified on either side of the perforation, the largest measuring $10 \mathrm{~cm}$ in diameter. As such, a segment measuring approximately $1 \mathrm{~m}$ in length, and containing roughly $95 \%$ of all visualised diverticula was resected (figures 2 and 3). The patient had an uncomplicated postoperative course. By postoperative day 3, he was tolerating a regular
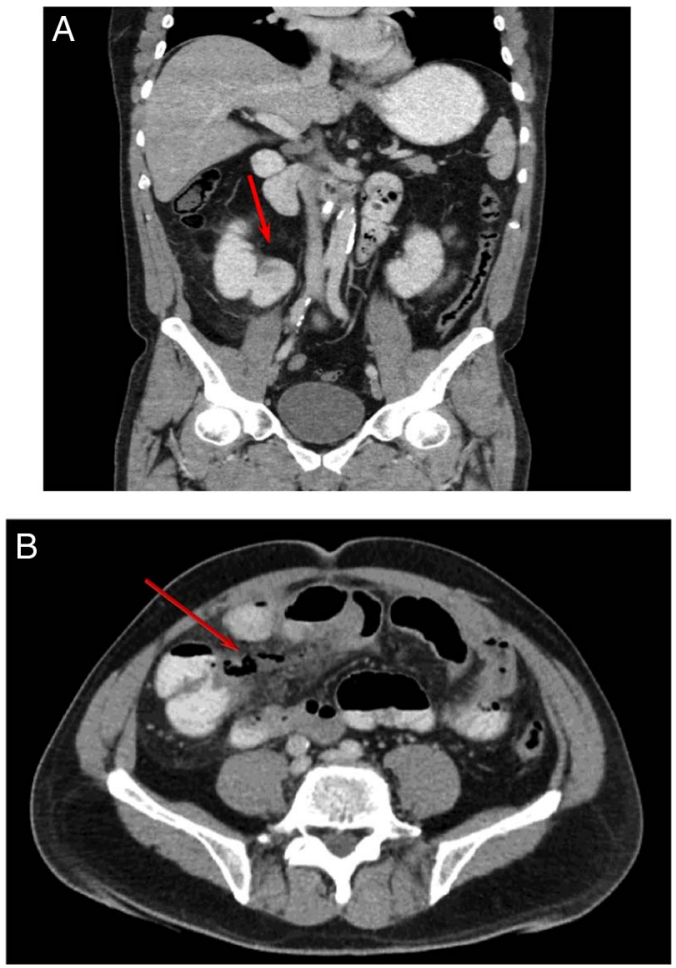

Figure 1 (A) CT of the abdomen and pelvis (coronal view) suggestive of a communication between adjacent loops of small bowel (red arrow). (B) CT of the abdomen and pelvis (transverse view) demonstrates the presence of extra luminal gas (red arrow) in the absence of pneumoperitoneum. 


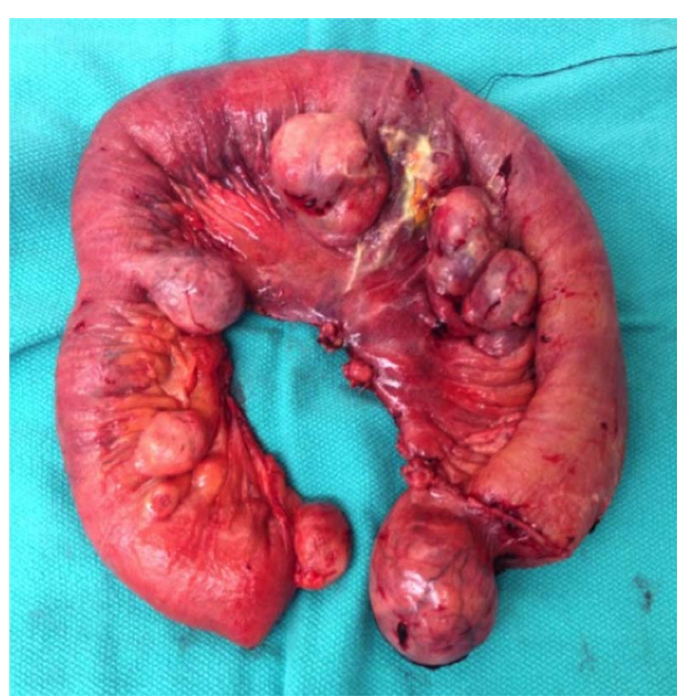

Figure 2 Resected intraoperative specimen showing the area of perforation, which is covered with fibrinous debris. This segment measured $1 \mathrm{~m}$ and contained $95 \%$ of the visualised diverticula, including the largest (bottom right), which measured roughly $10 \mathrm{~cm}$ in diameter.

diet and his bowel function returned, thus he was discharged home.

\section{OUTCOME AND FOLLOW-UP}

The patient had an uncomplicated postoperative course and was discharged home on postoperative day 3 . He continues to do well after 3 months, and has already gained $5 \mathrm{~kg}$.

\section{DISCUSSION}

Acquired diverticulosis of the small bowel was first described in 1794 by Sommering, and later in 1807 by Sir Astley Cooper. ${ }^{3}$ Although the true aetiology has not been fully elucidated and is likely multifactorial, it is thought to develop as a result of peristaltic deficiencies and intestinal dyskinesia leading to high segmental pressures. As a result, herniation of the mucosa and submucosa occurs on the antimesenteric border, which is made vulnerable by the entry of mesenteric vessels. ${ }^{1}{ }^{4-8}$ Among the

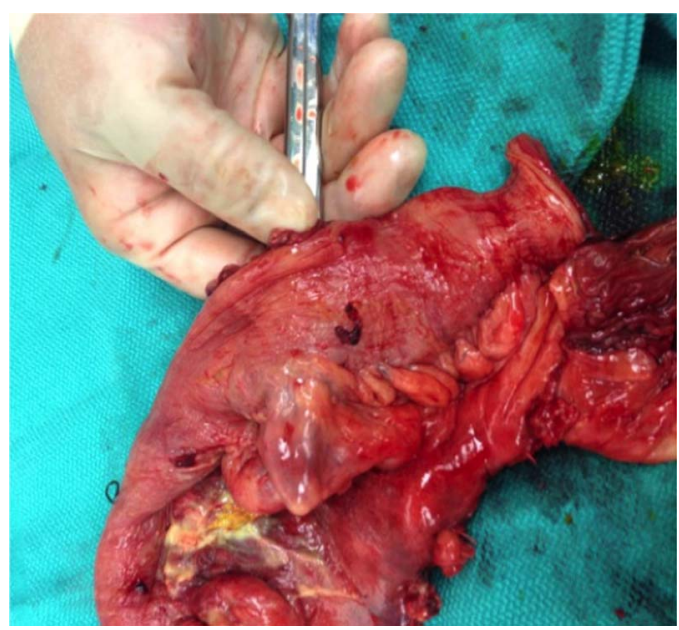

Figure 3 Invagination of a diverticulum in the resected specimen reflects how comparatively thin-walled the lesions are versus adjacent normal bowel wall. postulate causes, abnormalities in smooth muscle or of the myenteric plexus and functional deficiencies have proven casual associations. $^{3}$ As it relates to multiple giant jejunal diverticula (greater than $5 \mathrm{~cm}$ ) with evidence of malabsorption and perforation, as in our patient, occurrence in association with Elhers-Danlos syndrome has been described. ${ }^{9}$

Historically, jejunal diverticula have been considered to be clinically silent in the vast majority of cases. The incidence of symptomatic diverticular disease is estimated at $0.5 \%$, however, may be underestimated by virtue of the non-specific complaints it is typically associated with. The triad of 'flatulent dyspepsia', consisting of vague cramping abdominal pain, postprandial flatulence and diarrhoea, is often attributed to uncontrolled gastro-oesophageal reflux disease or small bowel enteropathies. ${ }^{4}$ This may explain why upwards of $15 \%$ of those affected will develop complications that require operative intervention, namely bleeding, obstruction and perforation. ${ }^{2}$ In comparison to duodenal diverticulosis, jejunal diverticula are nearly 18 times more likely to perforate, ${ }^{10}$ as such, some advocate for segmental resection in those with chronic symptoms following direct visualisation of diverticula via laparoscopy, in order to avoid the sequelae of advanced disease. ${ }^{2} 11$

What is unique to the diverticular process as compared with small bowel enteropathies is that stasis and bacterial overgrowth are prominent, especially in so-called 'giant' lesions. ${ }^{11}$ As such, hyperbilirubinaemia can occur both via malabsorption and by bacterial mediated deconjugation. This may explain the finding of elevated bilirubin in our patient in conjunction with urobilinogen. Bacteria also release siderophores and upregulate hepcidin, which can cause anaemia. Therefore, in those patients with a persistence of non-specific abdominal symptoms in the setting of elevations in bilirubin and anaemia, there should be high suspicion of jejunal diverticulosis.

Even when small bowel diverticula are considered, there is a significant challenge in achieving diagnostic confirmation. It should be noted that diagnosis is not necessary in the asymptomatic population since small bowel diverticulosis without symptoms or complications does not warrant treatment. Double-balloon enteroscopy is emerging as a useful modality in the localisation and management of bleeding diverticula, which avoids the need for bowel resection. ${ }^{12}$ Capsule endoscopy has been described as a viable investigative tool for symptomatic patients in the elective setting. However, it carries the inherent risk of retained capsule, and diagnostic efficacy in this setting has yet to be determined. In the setting of active diverticulitis or perforation, CT scans often demonstrate bowel wall thickening, and may reveal a localised abscess or evidence of free perforation. ${ }^{5}$ In short, at the present time, direct visualisation of diverticula is the only means of confirmation. In patients with a constellation of symptoms that have persisted despite multiple medical approaches, diagnostic laparoscopy may be the only definitive option. This is controversial though, considering the inherent risk of pursuing an invasive option on suspicion of uncomplicated disease. It should also be said that small bowel diverticula are often buried in the mesenteric fat and thus are not always readily identifiable.

In the case of free perforation and peritonitis, segmental resection and primary anastomosis remains the preferred intervention. $^{2} 711$ Since in most patients, diverticula will occur predominantly in the proximal jejunum, the goal of resection should be to involve the perforated segment as well as noninvolved visualised diverticula proximal to it. Where the disease is more diffuse, resection should be limited to avoid short bowel syndrome. Other described procedures such as simple closure, 
excision and invagination, are associated with a nearly threefold increase in mortality rate. Simple diverticulectomy is thought to have the potential to disturb blood flow given its mesenteric location, and thus creates the potential for anastomotic breakdown or fistula formation. ${ }^{8}$ There is some evidence to support lavage and drainage in the setting of contained micro perforation followed by a continuation of conservative management. This however is to be reserved a means to avoid small bowel resection in high-risk patient groups. ${ }^{13} 14$

Perforated jejunal diverticulitis is a rare acquired condition. While there is emerging evidence for the role of conservative management in the case of microperforation ${ }^{13} 14$ the concern for progression to free perforation, especially in the setting of large lesions, makes segmental resection the preferred intervention.

\section{Learning points}

- Jejunal diverticulosis is a rare clinical entity; however, its true incidence may be masked by the non-specific manner in which it typically presents.

- The rate of serious complications requiring operative management, such as bleeding and perforation, can be upwards of $15 \%$.

- Conventional diagnostic modalities are not specific for this process, and options are further limited in the setting of an acute abdomen. Diagnostic laparoscopy is advocated in patients with suspected disease.

- While conservative management may have a role in high-risk patients with small contained perforation, segmental resection remains the intervention of choice for free perforation.
Contributors CKav, CKao, and KS were involved in drafting the manuscript. PFF critically revised the manuscript. All the authors participated in the management of this patient while hospitalised.

Competing interests None.

Patient consent Obtained.

Provenance and peer review Not commissioned; externally peer reviewed.

\section{REFERENCES}

1 Zager JS, Garbus JE, Shaw JP, et al. Jejunal diverticulosis: a rare entity with multiple presentations, a series of cases. Dig Surg 2000;17:643-5.

2 Wilcox RD, Shatney $\mathrm{CH}$. Surgical significance of acquired ileal diverticulosis. Am Surg 1990;56:222-5.

3 Krisnamurthy $\mathrm{S}$, Kelly MM, Rohrmann CA, et al. Jejunal diverticulosis. A heterogeneous disorder caused by a variety of abnormalities of smooth muscle or myenteric plexus. Gastroenterol 1983;85:538-47.

4 Edwards HC. Diverticula of the small intestine. Br J Radiol 1949;22:437-42.

5 Hyland R, Chalmers A. CT features of jejunal pathology. Clin Radiol 2007:62:1154-62.

6 Kongara KR, Soffer EE. Intestinal motility in small bowel diverticulosis: a case report and review of literature. J Clin Gastroenterol 2000;30:84-6.

7 Roses DF, Gouge TH, Scher KS, et al. Perforated diverticula of the jejunum and ileum. Am J Surg 1976;132:649-52.

8 Ross CB, Richards WO, Sharp KW, et al. Diverticular disease of the jejunum and its complications. Am Surg 1990;56:319-24.

9 McLean AM, Paul RE Jr, Kritzman J, et al. Malabsorption in marfan (Ehlers-Danlos) syndrome. J Clin Gastroenterol 1985;7:304-8.

10 Chendrasekhar A, Timberlake GA. Perforated jejunal diverticula: an analysis of reported cases. Am Surg 1995;61:984-8.

11 Mattioni R, Lolli E, Barbieri A, et al. Perforated jejunal diverticulitis: personal experience and diagnostic with therapeutical considerations. Ann Ital Chir 2000;71:95-8.

12 Chen TH, Chiu CT, Lin WP, et al. Application of double-balloon enteroscopy in jejunal diverticular bleeding. World J Gastroenterol 2010;16:5616-20.

13 Spasojevic M, Naesgaard JM, Ignjatovic D. Perforated midgut diverticulitis: revisited. World J Gastroenterol 2012;18:4714-20.

14 Myers E, Hurley M, O'Sullivan GC, et al. Laparoscopic peritoneal lavage for generalized peritonitis due to perforated diverticulitis. Br J Surg 2008;95:97-101.

Copyright 2014 BMJ Publishing Group. All rights reserved. For permission to reuse any of this content visit

http://group.bmj.com/group/rights-licensing/permissions.

BMJ Case Report Fellows may re-use this article for personal use and teaching without any further permission.

Become a Fellow of BMJ Case Reports today and you can:

- Submit as many cases as you like

- Enjoy fast sympathetic peer review and rapid publication of accepted articles

- Access all the published articles

- Re-use any of the published material for personal use and teaching without further permission

For information on Institutional Fellowships contact consortiasales@bmjgroup.com

Visit casereports.bmj.com for more articles like this and to become a Fellow 